\title{
CHLOROGIN: USE OF SATELLITE AND IN SITU DATA IN SUPPORT OF ECOSYSTEM-BASED MANAGEMENT OF MARINE RESOURCES
}

\author{
Shubha Sathyendranath ${ }^{(1)}$, Justin Ahanhanzo ${ }^{(2)}$, Stewart Bernard ${ }^{(3)}$, Valborg Byfield $^{(4)}$, Lisa Delaney ${ }^{(5)}$, Mark \\ Dowell $^{(6)}$, John Field ${ }^{(7)}$, Steve Groom ${ }^{(8)}$, Nick Hardman-Mountford ${ }^{(8)}$, Nicolas Hoepffner ${ }^{(6)}$, Tim Jacobs ${ }^{(9)}$, \\ Milton Kampel ${ }^{(10)}$, Srinivas Kumar ${ }^{(11)}$, Vivian Lutz ${ }^{(12)}$, Trevor Platt ${ }^{(1)}$ \\ (1) Plymouth Marine Laboratory, Prospect Place, The Hoe, Plymouth PL1 3DH, UK, \\ Email: shubha.sathyendranath@dal.ca; tplatt@dal.ca \\ (2) UNESCO (United Nations Educational, Scientific and Cultural Organization), Intergovernmental Oceanographic \\ Commission, 1 rue Miollis, 75732 Paris Cedex 15, France, Email: J.Ahanhanzo@unesco.org

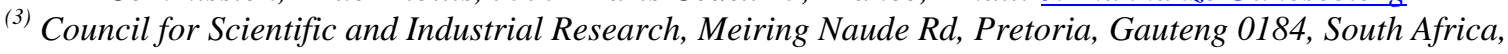 \\ Email: sbernard@csir.co.za \\ (4) National Oceanography Centre Southampton, University of Southampton Waterfront Campus, European Way, \\ Southampton SO14 3ZH, UK, Email: valborg@noc.soton.ac.uk \\ ${ }^{(5)}$ Dalhousie University, Department of Oceanography, 1355 Oxford Street, Halifax, NS Canada, B3H 4J1, \\ Email: lisa.delaney@dal.ca \\ ${ }^{(6)}$ European Commission, Joint Research Centre, Via E. Fermi, 2749 I-21027 Ispra (VA), Italy, \\ Email: mark.dowell@jrc.ec.europa.eu; nicolas.hoepffner@jrc.it \\ (7) Marine Research (MA-RE) Institute, University of Cape Town, P Bag X 3, Rondebosch 7701, South Africa, \\ Email: jgfielduct@gmail.com \\ ${ }^{(8)}$ Plymouth Marine Laboratory, Prospect Place, The Hoe, Plymouth PL1 3DH, UK, Email: sbg@pml.ac.uk; \\ nhmo@pml.ac.uk \\ (9) Vision on Technology (Vito), Boeretang 200, B-2400 Mol, Belgium, Email: tim.jacobs@vito.be \\ ${ }^{(10)}$ National Institute for Space Research (INPE), Av dos Astronautas, 1.758, Jd. Granja - CEP: 12227-010, São José \\ dos Campos - SP, Brazil, Email: milton@ltid.inpe.br \\ (11) Indian National Centre for Ocean Information Services, "Ocean Valley", P.B No.21, IDA Jeedimetla P.O, \\ Hyderabad - 500 055, India, Email: srinivas@incois.gov.in \\ ${ }^{(12)}$ Instituto Nacional de Investifación y Desarrollo Pesquero, Paseo Victoria Ocampo No 1, Escollera Norte, \\ B7602HSA Mar del Plata, Buenos Aires, Argentina, Email: vlutz@inidep.edu.ar
}

\section{INTRODUCTION}

As operational oceanography grows scientifically and expands as a practical discipline, the demand has been growing for data and information relevant to understanding the marine ecosystem at the global level, unravelling the functions of the marine ecosystem in a changing climate, and contributing to sustainable management of marine resources. As the importance of an ecosystem-based approach to the stewardship of the oceans is being increasingly recognised, opportunities are emerging for observing the ocean ecosystem at unprecedented resolution at the global scale, in a systematic and sustained manner, using satellite data. At the same time, it is well-recognised that combining satellite data with in situ observations in a judicial manner allows extension of applications to domains inaccessible by either method in isolation. In this context, there is a need for establishing a network of observations that relies on existing technology and well-established methods for making the measurements. The approach has to be simple and fast, to allow routine measurements over long time scales, and not to exclude some countries from participating, on the basis of high technological requirements or high operational costs.

The Chlorophyll Global Integrated Network (ChloroGIN) was developed in this context as a GOOS/GEO (Global Ocean Observing System/Group on Earth Observations) demonstration project focussed on issues related to marine ecosystems that aims to bring together regional satellite data processing centres in developing and developed countries, in situ data gathering efforts and users of the data. The project was initiated following recommendations of the "Plymouth Chlorophyll Meeting and Workshops (Extended Antares (Sustained Coastal Observing System for Latin America) Network)" sponsored by GOOS, GEO, IOCCG (International Ocean Colour Coordinating Group), PML (Plymouth Marine Laboratory) and POGO (Partnership for Observing the Global Oceans), 18 - 22 Sept 2006. ChloroGIN was inspired by the Antares network (www.antares.ws) that provides satellite coverage over Latin America, with links to a series of in situ time-series stations around Latin America in coastal waters. The two main objectives of ChloroGIN are (a) to deliver maps of ocean 
chlorophyll and sea-surface temperature, as the basis for developing ecosystem indicators needed for stewardship of the oceans [1] and [2] and (b) at related in situ time series sites, to provide a measure of chlorophyll, temperature and if possible, light penetration into the ocean e.g. [3] and [4]. These variables are needed to develop regional satellite algorithms for phytoplankton biomass and to calculate phytoplankton primary production. These are three of the core variables recommended for the Global Coastal Network listed in the GOOS Coastal Panel strategic plan.

ChloroGIN provides the framework under which a number of capacity building and data dissemination activities are being undertaken. ChloroGIN can also be seen as a contribution to the Global Earth Observation System of Systems (GEOSS) of the Group on Earth Observations (GEO) through the GEO task EC-06-07 (and in the 2009-2011 workplan in EC-09-01: Ecosystem Observation and Monitoring Network (GEO EcoNet) task EC-09-01 Regional Networks for Ecosystems). In addition to the Ecosystems Societal Benefit Area (SBA) with which ChloroGIN is explicitly associated, the activities undertaken by the network are of relevance, and will contribute to, many other SBAs that GEO addresses. These include the Agriculture SBA through the global fisheries and aquaculture project SAFARI (Societal Applications in Fisheries and Aquaculture using Remotely-sensed Imagery) (AG-06-02), the Water SBA through the global water-quality monitoring sub-task (WA-06-07d) and as an overarching initiative relevant to all of the coastal projects in the GEO Coastal Zone Community of Practice (CZCP). To all of these GEO initiatives, it is the long-term goal of ChloroGIN to provide a framework, a series of relevant products and associated services to ensure that the specific applications that these tasks address have access to consistent and intercomparable ocean-colour products. ChloroGIN itself has specific requirements in the context of GEO: the network requires uninterrupted, consistent and sustained provision of ocean-colour radiometry data into the future. Another task in the GEO workplan related to the virtual constellations, and in particular the virtual constellation of ocean colour radiometers (AR-09-02a), is expected to foster the long-term commitment necessary to guarantee the uninterrupted flow of Earth-observation data into the future.

\section{CURRENT ACTIVITIES}

Current activities include maintenance of the ChloroGIN (Chlorophyll Global Integrated Network) web portal (www.chlorogin.org) that provides a link to near-real time and archived measurements of remotelysensed ocean-colour products and SST (Sea Surface Temperature) for South America, Africa and the Indian Ocean.

ChloroGIN also provides the focus of the marine component of an European Commission funded project called DevCoCast (GEONETCast (Group on Earth Observations - global network of satellite based data dissemination systems) for and by Developing Countries). DevCoCast is disseminating data from sources in North and South America, Africa and Europe to user communities in South America, Africa and China in near-real time, via the EUMETCast (Broadcast system of the European Organisation for the Exploitation of Meteorological Satellites) satellite broadcasting system (operated by EUMETSAT), one of the 3 components of the GEO sponsored GEONETCast infrastructure (GEO task CB-06-04). The GEONETCast system is particularly valuable for disseminating environmental data where the internet infrastructure is relatively poor. Use of the products is promoted and supported through training workshops and the development of hands-on training material based on selected case studies from local ecosystems.

The participants of ChloroGIN have begun to explore adoption of best-practice common protocols for the core measurements at all sites. The first step towards recommending the best method for the determination of the key variable chlorophyll-a was attained through a hands-on training at the workshop 'The Chlorophyll Pilot Study (Enhanced Antares Network)' in Plymouth in 2006, and by an inter-calibration exercise carried out after the meeting where most laboratories potentially joining the network participated (Lutz et al. webreference in 'Publications' at www.antares.ws). This first evaluation identified some disparity in the quality of the data, some recommendations were enunciated, and some limitations recognized. The recommendations took into account the need for 'operational' measurements that could be easily standardized across all participating countries, developed and developing. 
ChloroGIN is conceived as a network of networks, facilitating access to relevant data for the user. They have a common framework, but the structure allows for regional enhancements to meet regional and local priorities. It builds on regional strengths and capacity, using networking as a mechanism for further development. This approach has facilitated growth, and set a model for capacity building within GEO. The main regional nodes of ChloroGIN are described below.

\section{Regional Nodes}

\subsection{ChloroGIN Canada:}

The time series for the NW Atlantic Ocean [5], [1] and [2] was initiated since the launch of SeaWiFS (Seaviewing Wide Field of View Sensor) in 1997 as a contribution to the development of strategies for ecosystem-based management of marine resources. It has served as an important tool for teaching and capacity building, which led to the development of Antares, and subsequently ChloroGIN. It was the first of its kind designed to follow the time course of pelagic ecosystem indicators for a particular region. It has provided the basis for papers relating ecosystem phenology with interannual variability in survival of larval fish [6] and with basin-scale variations in the life cycle of a commercially-important invertebrate [7]. The series is available to the public at http://starfish.mar.dfompo.gc.ca/science/ocean/ias/seawifs/seawifs 1. html .

\subsection{ChloroGIN Africa:}

The African component of ChloroGIN links together existing remote-sensing servers and information systems to provide high resolution $(1-\mathrm{km})$ products for northern and western Africa (Plymouth Marine Laboratory) and southern Africa (the multi-institutional Marine Remote Sensing Unit), whereas lowerresolution data for the whole of Africa are available via a web-based geographical information system (GIS, from the EC Joint Research Centre). These provide an integrated and easy-to-use ocean observing and data dissemination system. A primary focus of ChloroGINAfrica is sustainable capacity development, and the project fosters an integrated development environment through synergy with the African Large Marine Ecosystem Projects and other African marine research and development projects including the Global Ocean Observing Systems in Africa (GOOS-AFRICA) and the UNESCO (United Nations Educational Scientific and Cultural Organization) Crosscutting project on the Applications of Satellite Remote Sensing for Integrated Management of Ecosystems and Water Resources in Africa.

\subsection{ChloroGIN Indian Ocean:}

The GOOS Regional Alliance in the Indian Ocean (IOGOOS) has endorsed the Indian Ocean ChloroGIN Project as one of its pilot projects and identified the Indian National Centre for Ocean Information Services (INCOIS) as the coordinating and implementing agency. At the IOGOOS Annual Meeting held at Phuket in December 2007, IOGOOS Members endorsed the ChloroGIN Project and requested IOGOOS Secretariat and INCOIS to provide real-time Satellite Products (Chlorophyll, SST, Kd-490 and Suspended Sediments) for the coastal regions of Tanzania, Iran, Kenya, Sri Lanka, Maldives, Oman and Thailand. Since December 2008, INCOIS has provided MODIS (Moderate Resolution Imaging Spectroradiometer)-Aqua data in near real-time (NRT) mode to all the participating countries through an ftpbased sever. An automatic data processing chain has been setup at INCOIS to process and map MODIS data for the area bounding $40^{\circ} \mathrm{S}$ to $31^{\circ} \mathrm{N}$ and $35^{\circ} \mathrm{E}$ to $103^{\circ} \mathrm{E}$. Daily imagery, weekly and monthly composites of the four products are being disseminated through INCOIS website in three file formats: PNG (Portable Network Graphics), HDF (Hierarchical Data Format), and GeoTiff (Portable Network Graphics format.tif (Tagged Image File). Full-resolution products $(1 \mathrm{Km})$ are being provided for the IOGOOS member institutions in participating countries. The data products are staged on http://www.incois.gov.in/Incois/pfzarchiveimages1.ht

$\underline{\mathrm{ml}}$. Current efforts are focused on integrating the products from the upcoming OCM2 (Ocean Colour Monitor) data of ISRO (Indian Space Research Organization) and the MERIS (Medium Resolution Imaging Spectrometer) data from ESA (European Space Agency) into the processing chain.

Under India's Satellite Coastal Oceanographic Research (SATCORE) Program, eight time-series stations have been established in coastal waters off the eastern and western coasts of India, to make monthly measurements of chlorophyll, TSM (Total Suspended Matter), bio-optical properties using profiling radiometers, and a suite of biogeochemical variables, by fostering research among the participating national institutes. Samples collected from all the locations are centrally analyzed at a state-of-the-art laboratory funded by INCOIS. These facilities will be made available to the other participating countries in the Indian Ocean Region. A UNESCO/IOC (International Ocean Colour) sponsored workshop on Tsunami Modelling, Inundation Mapping and Remote Sensing was organized at INCOIS during October 27 to November 7, 2008, wherein participants involved in the Indian Ocean ChloroGIN project were trained on Ocean Colour Data processing and applications. 
This project entitled "Real-time Chlorophyll Mapping and Applications" by IOGOOS has now been included in the Revised Strategic Plan of IOGOOS that was adopted during the recent IOGOOS Annual Meeting held at Hyderabad, India in December 2008. A work plan was drawn up for 2009. Some of the actions planned are to: (i) Identify sites for in situ time series measurements in the Indian Ocean Region; (ii) Finalise in situ sampling strategy and protocols; (iii) Conduct training for member countries on ocean-colour applications, in situ sampling and data analysis; and (iv) Set up a web-GIS interface for data dissemination. A business proposal is being drafted for seeking funds from international donors for establishing a network of in situ time-series stations in the participating countries in addition to those established in India, and for capacity building in the region.

\subsection{ChloroGIN Antares:}

There were originally five field sites in South America; which were increased recently to a total of eight in Latin America (Antares webpage www.antares.ws for further details). The current participating countries are Argentina, Brazil, Canada, Chile, Colombia, Mexico, USA and Venezuela. The incorporation of new sites already carrying out time-series studies is highly encouraged, but all participating sites are requested to meet certain minimum requirements (see Antares webpage). It was agreed that the sites should be at a distance from land to allow the correct validation of satellite retrieved properties. The adequate frequency of sampling was established at once a month. For Antares/ChloroGIN the 'core' observations are seawater temperature and chlorophyll-a concentration; with light measurements being a highly-desired third variable. In addition to this set of core measurements, participants are encouraged to make a broader set of measurements to pursue local interests at the different sites, which ultimately could enhance the information of the whole network. Satellite information covering a number of areas of interest, surrounding the points of field sampling, is being processed daily and automatically displayed and up-loaded in the Antares webpage by the Institute of Marine Remote Sensing at the University of South Florida (USA). This type of web access to in situ data is yet to be achieved.

Education and exchange of expertise is a major target of the network. In connection with this, a course was held in Brazil (Universidad de São Paulo, and 'Instituto Nacional de Pesquisas Espaciais) on 'Evaluation of satellite ocean-colour algorithms and products in coastal regions of Central and South America', which was sponsored by the Nippon Foundation and the Partnership for the Observation of the Global Oceans (POGO) through their Visiting Professorship Program. This course provided the opportunity for graduate students, as well as researchers already working in biooptics, from different countries in Latin America, to receive state-of-the-art lectures on the subject by renowned scientists, and hands-on practice on the use of new technologies. Two other concrete benefits included the incorporation of a new site to the network (Mexico), and the acquisition (on a long-term loan, courtesy of the visiting professor R. Frouin, Scripps Institute of Oceanography) of radiometers for some of the sites to measure the spectral reflectance of light from the ocean.

The benefits of a network for fisheries applications became apparent at the first meeting on 'Societal Applications in Fisheries and Aquaculture using Remotely-sensed Imagery (SAFARI)', held in Canada in 2008. The Antares network is an example which demonstrates that remote-sensing information (satellite chlorophyll in this case), if offered in a free and easyto-use format, will enable more people to use it in fisheries research and management. At the moment, at least five research groups in Argentina alone are starting to use satellite information provided through the Antares web-site for their research on the distribution and abundance of hake, red Patagonian shrimp, anchovy, king crab, and other coastal commercial fish species.

\subsection{ChloroGIN Europe:}

ChloroGIN Europe brings together a range of existing and new services for operational chlorophyll-based products across Europe, with the major focus at Plymouth Marine Laboratory (PML) and the European Commission's Joint Research Centre (JRC) in Italy. PML operates a satellite data processing facility (NEODAAS (Natural Environment Research Council (NERC) Earth Observation Data Acquisition and Analysis Service) for UK academic scientists and this includes near-real time transmission of data to research cruises to guide in situ sampling. PML also contributes data to various European projects through EC funding and to national UK marine monitoring agencies. Furthermore, PML maintains the ChloroGIN portal and provides data for a number of other regions such as Africa and Asia as noted above. It is also the focus for initial development of data integration and visualisation approaches as part of the European InterRisk project (see below). The JRC processes ocean-colour radiometry data at full resolution (1-2 $\mathrm{km}$ ) at pan-European scale (as well as for other regions of European interest, see ChloroGIN Africa above). The archive includes both the historical CZCS (Coastal Zone Color Scanner) datasets as well as data from the beginning of the SeaWiFS time-series (1997/8) up to present. The focus of the datasets produced is on delayed mode, quality-controlled products that are used primarily by European institutions (i.e.: the European 
Commission's Directorate General for the Environment, the European Environment Agency and the Marine Conventions) for their state-of-theenvironment reporting responsibilities. A significant component of the investment in producing the datasets is in the continuous validation of the products as well as the emphasis on developing regionally-tailored approaches. A major new project in Europe is MyOcean that will provide data and forecasting services both within Europe and (at lower resolution) globally. The ocean-colour team of MyOcean includes both JRC and PML, with the former undertaking global data reprocessing and the latter producing regionspecific products for the northwest European shelves and North East Atlantic.

In situ sampling is well developed in Europe: for example, PML undertakes weekly sampling at station L4 south of Plymouth for HPLC (High-Pressure Liquid Chromatography) chlorophyll-a, phytoplankton composition by microscope and a variety of physical, biological and chemical variables. Recently, an instrumented mooring was deployed at L4 that takes hourly measurements. These data are being integrated with satellite and numerical model forecasts with the InterRisk web-GIS as an exemplar for the planned ChloroGIN web-GIS (see below).

\section{CAPACITY BUILDING}

Since its inception, ChloroGIN has had a strong capacity building element. ChloroGIN is built around a global problem, and has been developed through a network of time-series sites. The minimum requirements for participating sites have been identified. However, some developing countries find it difficult to meet even the minimum requirements with the resources available. Since the problem is global in its nature, partners from developing countries cannot be left out of the network simply because they do not have all the necessary resources. Some international organizations point out that joining such a programme offers the 'prestige' or 'umbrella' that would facilitate the attraction of funds from local agencies. This is true in some cases, but in several developing countries, funds from local agencies are very scarce or almost non-existent. Other limitations are related to the fact that different countries have different political (social and scientific) organizations, and it is difficult in some cases to convey to the authorities the relevance of maintaining costly time-series studies in comparison with some other pressing local issues. Hence capacity building in these countries remains at the forefront of the activities of ChloroGIN. Outreach to convey to the broader public the importance of such measurements is also needed. The need for human resource development has to be recognised, as well as the lack of infrastructure in some areas. Various capacity building activities of POGO (Partnership for Observation of the Global Oceans) have been particularly beneficial with human resource development, but much more needs to be done.

\section{DATA INTEGRATION}

The network seeks to provide practical information on marine ecosystems for use at national and regional scales (e.g. Large Marine Ecosystems) from a combination of Earth observation data from satellites and in situ observations. The need for an improved understanding of ecosystem processes and dynamics will benefit from the integration of in situ and remotely-sensed data. Whereas the former can give information about, for example, the vertical structure of chlorophyll- $a$, main phytoplankton groups and specific rate constants (e.g. photosynthetic parameters) at a particular geographic location, the latter can provide information about the chlorophyll- $a$ field at the regional and global scales at daily to weekly intervals. The combination of both approaches can give estimates of important ecological variables, such as of the watercolumn integrated primary production.

A starting point for integration of in situ and remotelysensed data within the network could be a comparison of in situ and satellite chlorophyll- $a$ values at each location. This initial comparison will help, for example, to determine how well the global chlorophyll$a$ algorithms are working in the different areas, what the main characteristic scales of variability in a particular system are, and if they are being sampled at the proper resolution. An example of the potential application of this exercise is the characterization and understanding of phytoplankton bloom dynamics and their impacts on other components of the ecosystem. Since phytoplankton blooms can be beneficial (e.g. for the recruitment of species of economic importance) or detrimental (e.g. harmful algae), determining their timing, intensity, duration and spatial extension becomes an important issue.

It is anticipated that, as the network develops, a wider range of in situ data, such as high-frequency automatic bio-optical measurements (e.g. fluorescence, attenuation and reflectance) will be integrated.

Main points of justification for the integration of in situ with remotely-sensed data are:

- it facilitates development of local and regional algorithms;

- it helps interpretation of data for local ecosystem processes; 
- it gives oceanographic context for point measurements;

- it allows extrapolation of chlorophyll-a and derived fields (e.g. primary production) to three dimensions; and

- it enhances both operational and research work.

\section{THE FUTURE}

Looking to the future, ChloroGIN is already forming a conceptual model for capacity building activities focussed on Africa, Asia and Latin America, and the model is being extended to include a wider diversity of satellite data types and applications. For example, the network provided the model for an application to the European Commission to fund a Europe-Africa EO (Earth Observation) network for the marine sector encompassing all types of marine remote sensing. It will also form a nucleus around which to build capacity and maintain capacity for both technical and human infrastructure in developing countries to support the Millennium Development Goals. Addition of new regional nodes remains a goal. For example, a Far East node including efforts of Japan, Korea and China has been recommended, with Joji Ishizaka (Japan) as the initial contact.

To integrate data from the different participating centres from various regions, a web-based GIS (Geographical Information Systems) will be constructed (called ChloroGIS), based on the open standards approaches defined by the Open Geospatial Consortium (OGC). This will mean that data, such as images or data from in situ samples that are served using these standards, can be viewed via a common portal. The prototype system being developed in the European-Commission-funded InterRisk (Interoperables GMES (Global Monitoring for Environment and Security) services for environmental risk management in marine and coastal areas of Europe) project currently allows visual comparison of different satellite-data products (e.g. MODIS and MERIS) and satellite and model predictions. Methods are also being constructed that enable quantitative extraction and comparison of in situ data, from a single station or from an underway sampling system such as Ferrybox, with the corresponding satellite data. Plans are underway to extend these efforts to southern Africa. ChloroGIS should provide the "glue" to combine different data types and products from different users as will be required for the Global Earth Observation System of Systems.

Development of regional algorithms and their validation would be important goals of ChloroGIN, but a more ambitious goal is to establish uncertainties and errors in algorithms, especially for coastal waters. The lack of uncertainty estimates tends to reduce the value of ocean-colour data and regional estimates of errors is one of the biggest challenges facing the ocean-colour community, particularly in the context of climate change. When the uncertainties make the data unsuitable for certain applications, this has to be clearly noted, and alternate approaches to addressing the problem identified whenever possible. The nature of ocean colour necessitates a regional approach to uncertainty estimates and validation, and the ChloroGIN structure has a very important role to play: a network of this nature is the only way the community can work towards such validation. Regional capacity building is also vital - building the community expertise to allow region-specific ocean-colour validation in the global coastal ocean.

Since the vision is inclusive, with well-identified roles to play for all participating nodes, the emphasis on the in situ side of the network is on standardised, low-cost systems, and where possible, on autonomous systems. The goals for the technical component of capacity building include working towards easily implemented low-cost in situ observation networks that are readily inter-compared. The vision also incorporates the idea of developing regional centres of excellence for analyses of in situ samples, for example for pigment analyses by High-Performance Liquid Chromatography and phytoplankton identification and counts. With the decision to be inclusive of developing countries, comes challenges regarding funding. ChloroGIN members are seeking to address this challenge through the power of networking and mutual help, and exploring opportunities as and when they arise. ChloroGIN also recognises the need to specify the minimum requirements from ocean-colour satellites to meet the needs of the network, and will work with IOCCG towards this goal.

The ChloroGIN vision of a network of successful regional elements, each tailored to serve the regional needs, is global in scope: in concept and implementation, it mirrors the GEO System of Systems at the scale of the coastal ecosystem. Moreover, it is a successfully working realisation of this concept.

\section{REFERENCES}

1. Groom S., Martinez-Vicente V., Fishwick J., Tilstone G.H., Moore G.F., Smyth T.J., Harbour D. (2009) The Western English Channel Observatory: Optical characteristics of station L4, Journal of Marine Systems, 77, 278-295

2. Koeller, P., Fuentes-Yaco, C., Platt, T., Sathyendranath, S., Richards, A., Ouellet, P., Orr, D., Skúladóttir, U., Wieland, K., Savard, L., Aschan, M. - 2009 - Basin- 
scale coherence in phenology of shrimps and phytoplankton in the North Atlantic Ocean - Science, 324, 791-793, doi:10.1126/science.1170987.

3. Lutz V.A. Subramaniam, A., Negria, R.M., Silva, R.I, Carreto, J.I. (2006) Annual variations in bio-optical properties at the 'Estacio' $\mathrm{n}$ Permanente de Estudios Ambientales (EPEA)' coastal station, Argentina, Continental Shelf Research 26, 1093-1112

4. Platt, T, Fuentes-Yaco, C, \& Frank, K T (2003). Spring algal bloom and larval fish survival. Nature, 423 (22 May, 2003), 398-399.

5. Platt, T, \& Sathyendranath, S (1996). Biological oceanography and fisheries management. International Council for the Exploration of the Sea, CM 0, 3.

6. Platt, T., Sathyendranath, S., and Fuentes-Yaco, C. (2007). Biological oceanography and fisheries management: Perspective after ten years. ICES J. Mar. Sci., 64: 863-869.

7. Platt T, Sathyendranath S (2008) Ecological indicators for the pelagic zone of the ocean from remote sensing. Remote Sensing of Environment 112:3426-3436. 